\title{
Immunochemical Characterization of a Human High Molecular Weight - Melanoma Associated Antigen Identified with Monoclonal Antibodies
}

\author{
Barry S. Wilson ${ }^{1}$, Giovanna Ruberto ${ }^{2}$, and Soldano Ferrone \\ ${ }^{1}$ Department of Pathology, University of Michigan Medical School, \\ 1335 East Catherine Street, Ann Arbor, MI 48109 \\ ${ }^{2}$ Departments of Pathology and Surgery, College of Physicians and Surgeons of Columbia University, \\ New York, NY 10032, USA
}

\begin{abstract}
Summary. Sodium dodecyl sulfate polyacrylamide gel analysis of a high molecular weight (HMW) human melanoma associated antigen (MAA) defined by murine monoclonal antibodies revealed a number of distinct polypeptides ranging from 80,000 up to 280,000 daltons, in addition to an extremely heterogeneous group of components distributed over a wide range in apparent molecular weight (300,000-700,000 daltons). The 280,000 dalton and the larger heterogeneous molecular weight material are glycosylated since they are labeled with ${ }^{3} \mathrm{H}$-sugars. The $H M W-M A A$ is readily solubilized in the absence of detergents and the entire series of polypeptides fractionates together in the void volume of a Sephadex G200 column. Peptide maps of the various polypeptides of the HMW-MAA, generated by Staphylococcus aureus $V-8$ protease, are essentially the same except that some of the proteolytic fragments derived from the lower molecular weight polypeptides (80,000 daltons) are present in greater amounts than are similar fragments derived from the larger molecular weight polypeptides; the latter finding suggests that the complexity in molecular weight of the MAA may reflect combinations of several base subunits. Proteolytic cleavage of the $H M W-M A A$ generates a number of peptides ranging in molecular weight from 77,000 daltons to less than 12,000 daltons, which still react with monoclonal antibodies and can distinguish monoclonal antibodies specific for different antigenic determinants of this $M A A$.
\end{abstract}

\section{Introduction}

Serological analysis of human melanoma has identified various types of antigens not detectable on normal melanocytes and these antigens are referred to as melanoma-associated antigens (MAA). Clinical evidence suggests that these markers and the corresponding antibodies may play a role in the biology of the tumor, since the presence of antibodies in patients correlates with the stage of the disease [for review, see 18], and expression of some MAA is associated with a favorable clinical course [23]. Characterization of MAA was initially accomplished with antibodies from the sera of melanoma patients and from animals immunized with cultured melanoma cells or purified MAA. More recently, the hybridoma technique [15] has been applied to this problem and the efforts of several laboratories have resulted in the development of monoclonal antibodies to MAA [3, 4, 7, 9-11, 14, 17-19, 25, 28]. The availability of monoclonal antibodies has allowed for serolog-

Reprint requests should be addressed to S. Ferrone ical analysis at the antigenic determinant level and has facilitated the application of immunochemical approaches to define the structure of MAA. Several MAA have now been defined and their molecular profile characterized. These include MAA with single-chain structures [7, 10, 14, 18, 27, 28] as well as some composed of two or more polypeptide chains $[10,12,14,19,25]$. We have identified a multichain MAA of high molecular weight (HMW-MAA) which is expressed by melanomas, nevi, and some skin carcinomas but is undetectable on melanocytes and other normal and tumor tissues [19, 25]. In this paper we present an immunochemical analysis of this HMW-MAA, illustrating some of its unusual biochemical characteristics.

\section{Materials and Methods}

Radiolabeled Melanoma Cell Extracts. The melanoma cell lines M16, M21, and Colo38, maintained by serial passage in RPMI 1640 medium containing $10 \%$ calf serum, were surface labeled with ${ }^{125} \mathrm{I}$ (Amersham, Arlington Heights, IL, USA) using Iodogen as described by Salisbury and Graham [21]. Alternatively, cells were intrinsically labeled with ${ }^{3} \mathrm{H}$-sugars or with ${ }^{35} \mathrm{SO}_{4}$ (both from Amersham, Arlington Heights, IL, USA) as described previously [24]. Labeled cells were washed three times with phosphate-buffered saline (PBS) pH 7.0 and then shaken for $30 \mathrm{~min}$ at $4^{\circ} \mathrm{C}$ with 10 volumes of the appropriate extraction buffer (see Table 1) containing $10 \mu M$ of the fresh proteolytic inhibitor phenylmethylsulfonylfluoride. The extract was then cleared by centrifugation at $7,000 \mathrm{~g}$ and stored at $-20^{\circ} \mathrm{C}$. Extraction buffers containing $3 \mathrm{M} \mathrm{KCl}$ or urea were dialyzed against PBS prior to reaction with antibody-linked Sepharose.

Monoclonal Antibodies (MoAb) to the HMW-MAA. The production, serological analysis, and immunochemical characterization of the three monoclonal antibodies 138.13, 225.28S, and $653.40 \mathrm{~S}$, which react with the same or closely-associated antigenic determinant [13], have been described previously $[11,19,25,27]$. Briefly, MoAb 138.13 and 225.28S, both $\operatorname{IgG} 2 \mathrm{a}$, and $\mathrm{MoAb} 653.40$, IgG1, react in binding assays with cultured melanoma cell lines but not with cultured carcinoma and lymphoid cells $[19,25,27]$. Indirect immunofluorescence analysis on cryostat thin sections of human biopsy material showed that these monoclonal antibodies react with melanoma, nevi, and skin carcinomas but fail to react with a large variety of normal and malignant human cells [19, 25, 27]. 
Table 1. Solubilization of the high molecular weight MAA detected by monoclonal antibody $225.28 \mathrm{~S}$

\begin{tabular}{llll}
\hline Solubilization & \% Radio- & \% Radio- & $\%$ Total \\
conditions & activity & activity & HMW- \\
& solubilized & associated & MAA \\
& from cells ${ }^{\mathrm{a}}$ & with HMW- & solubi- \\
& & MAA from & lized $^{\mathrm{c}}$ \\
& & solubilized \\
& & \\
& & &
\end{tabular}

\begin{tabular}{llll}
\hline $\begin{array}{l}10 \mathrm{~m} M \text { phosphate } \\
\text { buffer pH 7.3 }\end{array}$ & 56 & 1 & 28 \\
$3 \mathrm{M} \mathrm{KCl}$ & 51 & 0.9 & 24 \\
$0.1 \mathrm{MUrea} / \mathrm{PBS}^{\mathrm{d}}$ & 36 & 0.6 & 11 \\
$1.0 \mathrm{MUrea} / \mathrm{PBS}$ & 43 & 0.5 & 12 \\
$1 \% \mathrm{NP} 40 / 10 \mathrm{~m} M$ & 67 & 2.7 & 91 \\
phosphate & & 2.6 & 100 \\
$1 \% \mathrm{NP} 40 / \mathrm{PBS}$ & 75 & \\
\hline
\end{tabular}

a Cells were surface-labeled with ${ }^{125} \mathrm{I}$ by the iodogen procedure

b Determined by immunoprecipitation with MoAb 225.28S

c Determined relative to NP40-PBs

d PBS, phosphate-buffered saline pH 7.1

Another monoclonal antibody, 149.53, produced as described previously except that the immunogen was melanoma cells Colo38, reacts with the same structure as the other three antibodies but identifies a spatially distinct antigenic determinant since MoAb 149.53 does not block the binding of MoAb 225.28S to the HMW-MAA [26].

Immunoadsorbent Purification of the HMW-MAA. The monoclonal antibodies isolated from ascites fluids by precipitation with $\mathrm{NH}_{4} \mathrm{SO}_{4}$ (33\% of saturation) were either covalently attached to Sepharose 4B (Pharmacia, Inc., Piscataway, NJ, USA) by the $\mathrm{CNBr}$ method [6] or bound to Protein A Sepharose 4B (Pharmacia). In most experiments a ratio of $5 \times 10^{6} \mathrm{cpm}{ }^{125} \mathrm{I}$ was reacted per $10 \mu \mathrm{l}$ packed immunoadsorbent diluted to approximately $0.5 \mathrm{ml}$ with NET buffer [1]. After $2 \mathrm{~h}$ rotation at $4^{\circ} \mathrm{C}$, the immunoadsorbent was washed seven times with NET and three times with PBS, prior to boiling for $2 \mathrm{~min}$ in $100 \mu \mathrm{l}$ SDS-sample buffer [16]. To obtain the higher concentrations of ${ }^{125}$ I-labeled antigen needed in the peptide mapping experiments, large volumes of immunoadsorbents $(1 \mathrm{ml})$ were eluted by boiling for $5 \mathrm{~min}$ with $0.2 \%$ SDS, concentrated by evaporation under vacuum, and then reconstituted to $1 / 10$ the elution volume with $0.125 M$ Tris buffer $\mathrm{pH} 6.8$.

Gel Electrophoresis. Polyacrylamide gel electrophoresis (PAGE) was performed in sodium dodecyl sulfate (SDS) using the buffer system described by Laemmli [16]. Gels were cast as $80 \times 1.5 \mathrm{~mm}$ slabs and electrophoresed at $3 \mathrm{mM} /$ gel constant current until the bromphenol blue tracking dye reached the bottom of the gel. The gels were stained with Coomassie blue in $40 \%$ methanol, $7.5 \%$ acetic acid, destained in $10 \%$ methanol, $10 \%$ acetic acid, and dried under vacuum. Kodak XAR-OMAT film was sandwiched between a dried gel and a Dupont Cronex High-plus intensifying screen for $1-6$ days at $-70^{\circ} \mathrm{C}$.

Peptide mapping by partial proteolysis in SDS was performed using the Cleveland method [5] as modified for two-dimensional analysis by Bordier and Crettol-Harviner [2].
The first dimension was done in $1.5 \mathrm{~mm}$ thick slab gels and the second dimension in $2 \mathrm{~mm}$ thick slab gels. The only modification used here was that the Staphylococcus aureus V-8 protease $(1 \mathrm{mg} / \mathrm{ml})$ (Miles Laboratories, Inc. Elkhart, IN, USA) was mixed with bovine serum albumin (Fract V, Miles Laboratories, Inc. Elkhart, IN, USA) $(1 \mathrm{mg} / \mathrm{ml})$ to insure a similar enzyme/substrate ratio over the entire width of the gel.

One-dimensional SDS-PAGE analysis of antigenically active proteolytic fragments detectable with monoclonal antibodies was performed as follows: a hypotonic extract of ${ }^{125}$ I-labeled melanoma cells Colo38 was digested at $37^{\circ} \mathrm{C}, \mathrm{pH} 7$ with trypsin $10 \mathrm{mg} / \mathrm{ml}$ (Sigma Chemical Co., St Louis, MO, USA), chymotrypsin (Sigma Chemical Col, St Louis, MO, USA), Pronase (Calbiochem, Behring, La Jolla, CA, USA), and V-8 protease from Staphylococcus aureus (Miles Laboratories, Inc., Elkhart, IN, USA).

\section{Results}

\section{Solubilization of the $H M W-M A A$}

Surface-radiolabeled melanoma cells Colo38 were extracted with various agents and the extracts were analyzed for the total amount of radioactivity specifically bound by insolubilized MoAb 225.28S (Table 1). The nonionic detergent NP40 was three times more efficient than either high- or low-salt in solubilizing the HMW-MAA; the least efficient extraction buffer contained either 0.1 or $1.0 \mathrm{M}$ urea. Using detergent solubilization, the MAA detected by MoAb 225.28S represented up to $2.5 \%$ of all the radioactivity released by the cells.

\section{Subunit Structure of the HMW-MAA}

An NP40PBS extract of surface-radioiodinated melanoma cells was reacted with MoAb 138.13, 149.53, 225.28S, 653.40S insolubilized to Sepharose $4 \mathrm{~B}$ and the bound antigens analyzed by SDS-PAGE. A representative gel pattern typical for all four monoclonal antibodies is shown in Fig. 1. Up to 12 distinct molecular-weight components can be seen when SDS-PAGE is performed in $7.5 \%$ polyacrylamide. The most typical size components are a very high molecular weight component at the top of the gel, a 280,000 dalton polypeptide, a 240,000 dalton polypeptide, a series of polypeptides of around 120,000 daltons, and three polypeptides around 80,000 daltons. Interestingly, the amount of ${ }^{125} \mathrm{I}$ associated with the various components is greatest at the highest molecular weight and decreases proportionally with polypeptide size. The mobility of these various components in SDS-PAGE is not changed in the absence of a reducing agent (2-mercaptoethanol), indicating that none of the components identified by the monoclonal antibodies are bridged by disulfide bonds (data not shown). It should be noted that immunoprecipitation of these ${ }^{125}$ I-labeled extracts with monoclonal antibodies to HLA-A, B antigens or to human Ia antigens and SDS-PAGE analysis showed the typical two-chain structures without evidence of technical artifacts.

To increase the mobility of the labeled component at the top of the $7.5 \%$ acrylamide gel and therefore obtain an estimate of its apparent molecular weight, gels containing different mixtures of polyacrylamide $(2 \%-5 \%)$ and agarose $(0.5 \%-1 \%)$ were tested for their ability to separate high molecular weight standards. A gel containing 3\% polyacrylamide and $0.75 \%$ agarose was chosen because it allowed the 


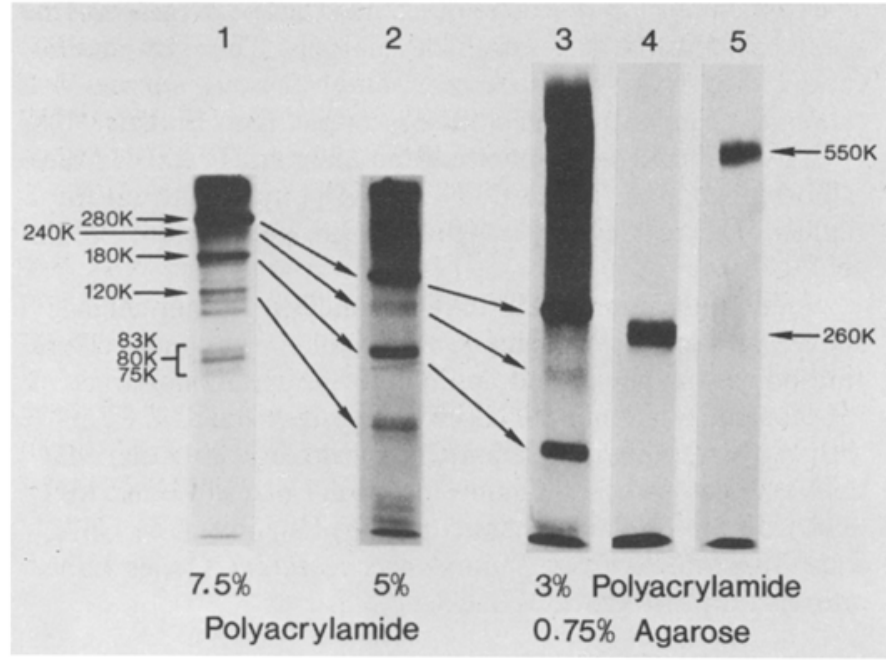

Fig. 1. Immunochemical analysis of the HMW-MAA detected by MoAb 225.28S. Melanoma cells Colo38 surface-labeled with ${ }^{125} \mathrm{I}$ and solubilized with NP40 were immunoprecipitated with MoAb 225.28S and analyzed by SDS-PAGE performed in different concentrations of polyacrylamide and agarose (lanes 1-3). Lanes 4 and 5 contain melanoma (Colo38) spent media fibronectin labeled with ${ }^{3} \mathrm{H}$-glucosamine and immunoprecipitated by a monoclonal antibody. Lanes $1-4$ were run under reducing conditions (2\%, 2-mercaptoethanol) best separation of fibronectin monomer ( 220,000 daltons) from the dimer (440,000 daltons) and was easy to handle. Electrophoresis of the MAA detected by MoAb 225.28S on a standard $5 \%$ polyacrylamide SDS gel and on the $3 \%$ polyacrylamide $/ 0.75 \%$ agarose SDS gel showed that the component from the top of the $7.5 \%$ polyacrylamide gels does not migrate as a single component but disperses over a large range in apparent molecular weight, from approximately 300,000 daltons up to 700,000 daltons. This extreme heterogeneity is not due to a technical artifact of the gel since human fibronectin from the spent culture medium of melanoma cell lines exhibits a restricted apparent molecular weight in both its monomer (260,000 daltons) and its dimer (550,000 daltons) forms (Fig. 1). Of the various molecular weight components detectable with the different monoclonal antibodies only the heterogeneous array of components at the top of the $7.5 \%$ gel and the 280,000 dalton structure can be labeled with ${ }^{3} \mathrm{H}$-sugars such as ${ }^{3} \mathrm{H}$-glucosamine, ${ }^{3} \mathrm{H}$-fucose, ${ }^{3} \mathrm{H}$-galactose, and ${ }^{3} \mathrm{H}$-mannose and with ${ }^{35} \mathrm{SO}_{4}$.

\section{Native Configuration of the HMW-MAA}

A hypotonic extract ( $10 \mathrm{~m} M$ phosphate buffer, $\mathrm{pH} 7.3)$ of radioiodinated melanoma cells Colo38 was subjected to gel filtration chromatography over Sephadex G200 and the resulting fractions analyzed for the HMW-MAA with insolu-

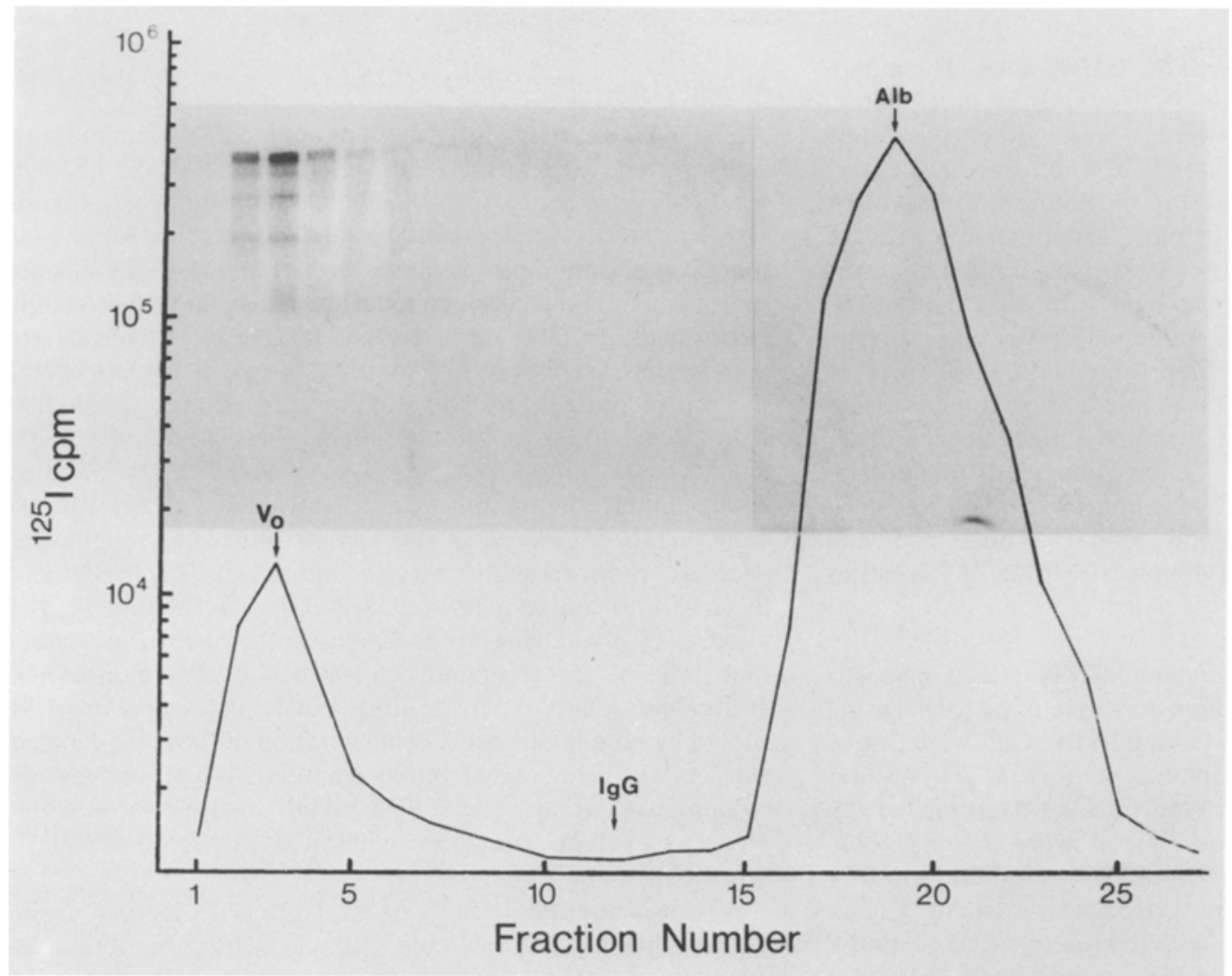

Fig. 2. Gel filtration analysis of the HMW-MAA detected by MoAb 225.28S. A hypotonic lysate (10 mM phosphate buffer pH 7.3) of ${ }^{125}$ I-surface-labeled melanoma cells Colo38 was fractionated over Sephadex G200. Two peaks of radioactivity were seen, one in the void volume $\mathrm{V}_{0}$, and the other larger peak cofractionates with serum albumin. Equal amounts of radioactivity from each fraction were immunoprecipitated with the MoAb 225.28S and analyzed by SDS-PAGE. The results are depicted above each fraction 
bilized MoAb 225.28S. The majority of the radioactivity applied to the column fractionates with a serum albumin marker $(70,000$ daltons), while a small peak of radioactivity coincided with the void volume (Fig. 2). The various polypeptides of the MAA detected by MoAb 225.28S were found to elute in the void volume fractions of the column. Thus, the presence of even the 80,000 dalton polypeptides of the MAA in the void volume rather than in the serum albumin peak $(70,000$ daltons) suggests that the series of components identified by MoAb225.28S exists as a complex in their native state.

The lack of change in the mobility of the components electrophoresed under nonreducing conditions argues against disulfide bridging and suggests that the components are apparently associated by noncovalent interactions.
Peptide Mapping of the Various Polypeptides of the HMW-MAA

The various ${ }^{125}$ I-labeled polypeptides identified by MoAb 225.28S were separated in the first dimension by SDS-PAGE, and a lane from this gel was placed at right angles over the top of a second SDS-polyacrylamide slab gel; after overlaying with Staphylococcus aureus V-8 protease, electrophoresis was performed in the usual manner. V-8 digestion generates two major groups of peptides, all below 10,000 daltons in molecular weight (Fig. 3). Close inspection of the autoradiograph reveals that each major group is composed of three distinct peptides, which are however nearly identical in molecular weight. The maps are essentially the same for all the

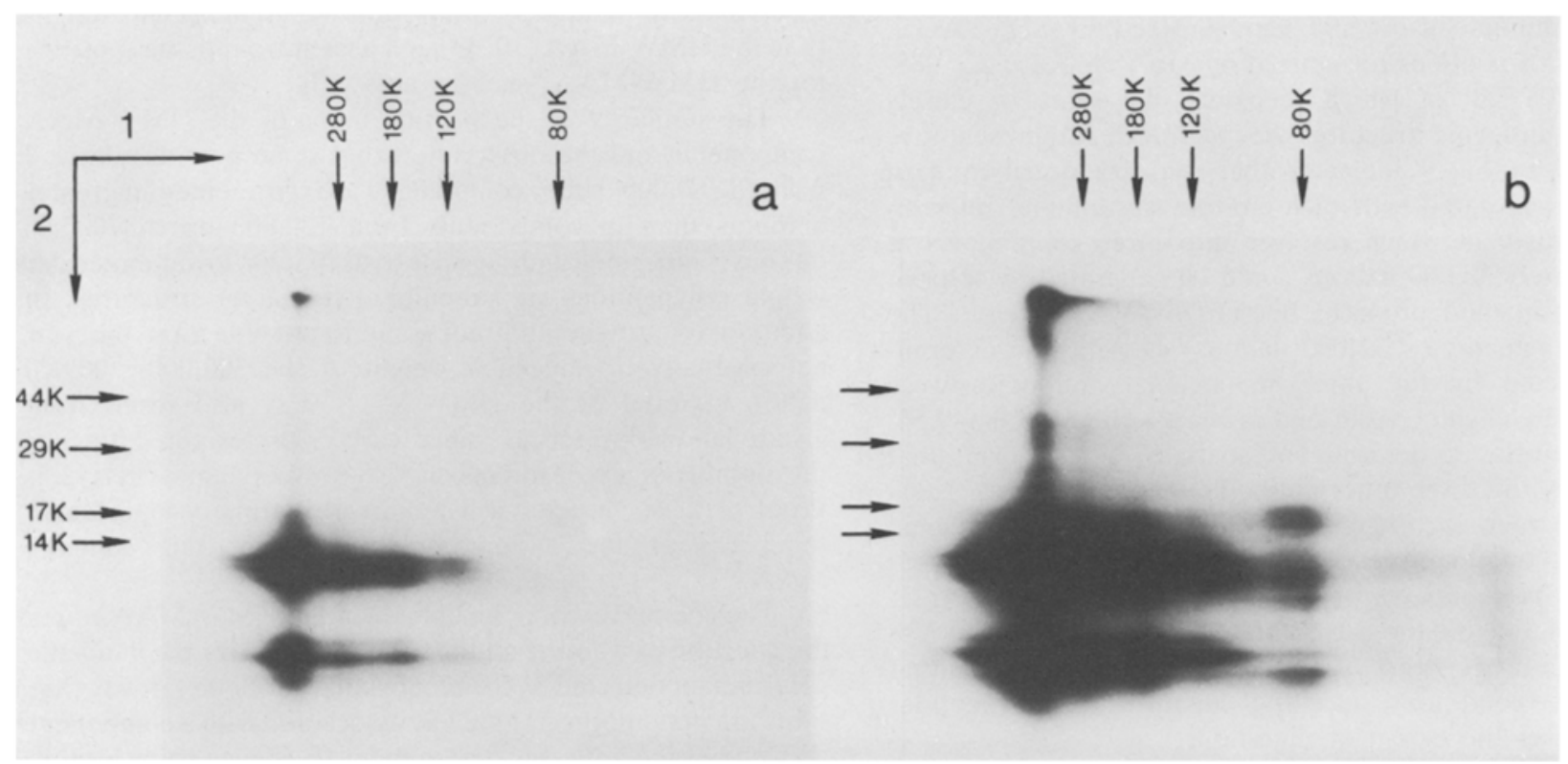

Fig. 3. One-dimensional peptide mapping of the HMW-MAA detected by MoAb 225.28S. ${ }^{125}$ I-labeled HMW-MAA were first immunoprecipitated and separated into the various components as described in Fig. 1. The first dimension lane containing the separated antigens was equilibrated in SDS stacking gel buffer, applied across the top of a standard $15 \%$ SDS gel and sealed in place with $1 \%$ agarose. A solution containing $1 \mathrm{mg}$ Staphylococcus aureus V-8 protease $\mathrm{ml} 0.5 \% \mathrm{SDS}$, and $0.05 \%$ Bromphenol blue was layered over the first dimension lane prior to the second dimension electrophoresis. Panels $\mathrm{A}$ and $\mathrm{B}$ differ in their time of exposure to X-ray film

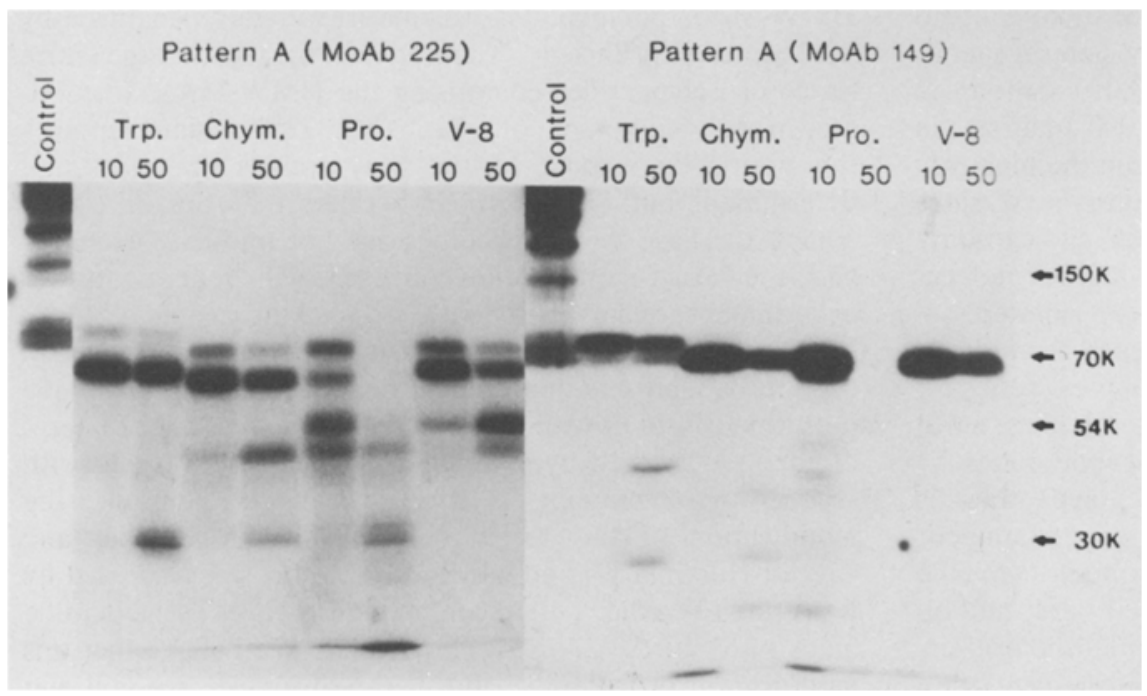

Fig. 4. Array of antigenically active peptides of the HMW-MAA detectable with MoAb 225.28S (left panel) and MoAb 149.53 (right panel). An NP40 detergent extract of ${ }^{125} \mathrm{I}$-surface-labeled melanoma cells was digested with 10 and $50 \mu \mathrm{g}$ enzymes $/ \mathrm{ml}$ for $60 \mathrm{~min}$ at $37^{\circ} \mathrm{C}$. The extracts were then immunoprecipitated at $4^{\circ} \mathrm{C}$ with the monoclonal antibodies bound to Sepharose $4 \mathrm{~B}$ and the bound peptides assessed by electrophoresis in a $10 \%$ SDS-polyacrylamide gel 
first dimensions components, with the amount of each peptide decreasing proportionally with the amount of radioactivity present prior to digestion; however, some peptides generated from the 80,000 dalton region first-dimension structure (upper and lower peptide grouping) are present in greater amounts (as evidenced by the degree of film exposure) than are peptides of similar molecular weight derived from the larger first-dimension components $(120,000$ up to 700,000 daltons $)$.

\section{Generation of Antigenically Active Proteolytic Fragments of the $H M W-M A A$}

A hypotonic extract $(10 \mathrm{~m} M$ phosphate buffer $\mathrm{pH} 7.3)$ of radioiodinated melanoma cells Colo38 was digested for $1 \mathrm{~h}$ with different concentrations of trypsin, chymotrypsin, pronase, and Staphylococcus aureus V-8 protease. The remaining antigenically active material was isolated on monoclonal antibody immunoadsorbents and analyzed by SDS-PAGE. The series of peptides recognized by MoAb 138.13, 225.285, and $653.40 \mathrm{~S}$, all of which recognize the same or closely associated antigenic structure, were identical. A representative gel shown in Fig. 4 indicates that the size distribution of fragments generated with each enzyme was unique. Interestingly, a fragment which resolves into three components at approximately 30,000 daltons could be generated by trypsin, chymotrypsin, and pronase, but not by $V-8$ protease. The smallest fragments $(<12,000$ daltons) carrying the determinant detected by the three monoclonal antibodies were generated by chymotrypsin and pronase. The MoAb 149.53, which identifies a determinant spatially distant from that detected by the three other antibodies reacts with the 77,000 dalton or larger-size fragments seen by the other monoclonal antibodies, but identifies little if any of the lower-molecular-weight fragments seen by the other antibodies (Fig. 4). It should be noted that the size of the fragments generated by V-8 proteases in the presence of SDS (Fig. 3) is different from that under native conditions, since SDS denatures the polypeptides and increases the extent of digestion.

\section{Discussion}

Immunochemical studies have shown that the HMW-MAA isolated from ${ }^{125} \mathrm{I}$-labeled melanoma cells with the MoAb 225.28S consists of a large number of distinct polypeptides with molecular weights ranging from about 80,000 daltons up to 280,000 daltons, in addition to an extremely heterogeneous group of polypeptides distributed over 400,000 daltons in apparent molecular weight $(300,000-700,000$ daltons in range). Only the 280,000 dalton component and the high-molecular-weight heterogeneous material are glycosylated, since they readily incorporate ${ }^{3} \mathrm{H}$-sugars. In addition, the carbohydrate portions of the 280,000 dalton and higher molecular weight components of the HMW-MAA are sulfated.

It seems unlikely that technical artifacts such as antibody contamination can have generated the complex series of polypeptides detected by these monoclonal antibodies, since (1) the hybridomas have been subcloned several times by limiting dilution and the same pattern of polypeptides is detected by more than 10 subclones that have been examined; and (2) we have now produced two antibodies to the HMW-MAA in addition to the four described here, and all identify the same series of polypeptides (unpublished observations). On the other hand, because of the high susceptibility of the HMW-MAA to proteolysis we cannot exclude that the lower molecular weight components represent cleavage products of the high molecular weight components during the solubilization procedure.

The structure of the HMW-MAA described in this study is similar to that of the MAA recently described by Bumol and Reisfeld [3]. An exchange of monoclonal antibodies during a workshop organized by the National Cancer Institutes of the National Institutes of Health has shown that the monoclonal antibody developed by Bumol and Reisfeld [3] and our monoclonal antibodies react with the same antigenic structure, although with different determinants. On the other hand, the tissue distribution and the structure of the HMW-MAA we have identified are different from those of other MAA described in the literature. The majority of MAA described have been single-chain structures $[7,10,14,18,27,28]$, while those that are multichain are both lower in molecular weight than the HMW-MAA $[10,14]$ and absent from tissues positive for the HMW-MAA, such as nevi [10].

The similarity in the peptide maps of the HMW-MAA components and the observation that some peptides derived from the 80,000 dalton components are represented in greater amounts than in components from 120,000 up to 700,000 daltons is intriguing and suggests to us that the lower molecular weight polypeptides are subunits of the larger structures. In addition to protein differences, it is possible that the vast heterogeneity in molecular weight of the 300,000-700,000 dalton material of the HMW-MAA may also result from glycosylation differences, since carbohydrates can influence the mobility of glycoproteins on SDS-polyacrylamide gels [22]. Proof of these theories will require the primary amino acid sequences of the various polypeptides of this complex MAA.

The complexity of polypeptides of the HMW-MAA raises the question of whether all the components carry the antigenic determinant detected by the monoclonal antibodies or whether some are immunoprecipitated by association with a component that carries the antigenic determinant. Evidence from peptide mapping showing a similar chemical composition for the various polypeptides of the HMW-MAA is consistent with the possibility that all the components carry the antigenic determinant detected by the monoclonal antibodies, although we have been unable to demonstrate antigenicity after the polypeptides have been separated by SDS-PAGE [27]. Whether this is a technical problem or whether the HMW-MAA polypeptides become irreversibly denatured by SDS is presently unclear. Alternatively, the fact that the entire series of polypeptides comprising the HMW-MAA fractionates in the void volume of a Sephadex G200 column supports the notion that some of the polypeptides may lack the determinant but are identified because they are part of a complex. These two possibilities are not mutually exclusive and the exact contribution of each will require further experiments, such as tests with crosslinking agents.

Some mention should be made of the techniques utilized in this study. The one-dimensional peptide mapping technique performed in SDS with Staphylococcus aureus V-8 protease, originally described by Cleveland [5], has been utilized with success by a number of investigators. In addition, the modification of this technique described by Bordier and Crettol-Harviner [2] and used in this report was also used by Reiser and Wardale [20] to compare differences in the peptide maps of SV40, VP2, and VP3 proteins. We believe that this modification of the Cleveland method provides a useful and 
simple way of comparing peptide maps of multichain structures. The gel with reduced concentrations of polyacrylamide (3\%) and containing $0.75 \%$ agarose for support was found ideal for separating fibronectin monomer from dimer while still achieving good resolution. This type of gel should be generally applicable for determining the molecular weight of very large glycoproteins.

An interesting characteristic of the HMW-MAA is its ability to be cleaved into proteolytic fragments that retain their antigenic activity. The isolation of immunologically active fragments will facilitate the assessment of the primary structure of key domains of this molecule. This information will be useful for in vitro synthesis of fragments of the HMW-MAA for clinical testing.

Acknowledgements. This work is supported by National Institutes of Health Grants AI 19189, CA 32609, CA 32619, CA 32634, and CA 32635, and a Research Cancer Development Award (1 KO4C 1100845-01, to B. S. Wilson).

Dr G. Ruberto is a visiting investigator from Clinica Medica $I^{\circ}$, Pavia, Italy.

\section{References}

1. Allison JP, Belvedere M, Reisfeld RA, Pellegrino MA, Ferrone S (1978) Serological and immunochemical characterization of HLA-A9 xenoantisera. J Immunol 121: 579-585

2. Bordier C, Crettol-Harviner A (1979) Peptide mapping of heterogeneous protein samples. J Biol Chem 254: 2565-2567

3. Bumol TF, Reisfeld RA (1982) Unique glycoprotein-proteoglycan complex defined by monoclonal antibody on human melanoma cells. Proc Natl Acad Sci USA 79: 1245-1249

4. Carrel S, Accolla RS, Carmagnola AL, Mach JP (1980) Common melanoma-associated antigen(s) detected by monoclonal antibodies. Cancer Res 40: 2523-2528

5. Cleveland DW, Fischer SG, Kirschner MW, Laemmli UK (1977) Peptide mapping by limited proteolysis in sodium dodecyl sulfate and analysis by gel electrophoresis. J Biol Chem 252: 1102-1106

6. Cuatrecasas P (1970) Protein purification by affinity chromatography. Derivativations of agarose and polyacrylamide beads. J Biol Chem 245: 3059-3065

7. Dippold WG, Lloyd KO, Li LTL, Ikeda H, Oettgen HF, Old LJ (1970) Cell surface antigens of human malignant melanoma; definition of six antigenic systems with mouse monoclonal antibodies. Proc Natl Acad Sci USA 77:6114-6118

8. Ferrone S, Pellegrino MA (1978) Antigens and antibodies in malignant melanoma. In: Waters $\mathrm{H}$ (ed) Handbook of cancer immunology. Garland Press, New York, p 291

9. Hellstrom I, Hellstrom KE, Yeh M (1981) Lymphocyte-dependent antibodies to antigens 3.1 , a cell-surface antigen expressed by a subgroup of human melanomas. Int $\mathbf{J}$ Cancer 27: $281-285$

10. Herlyn M, Clark WH, Mastrangelo MJ, Guerry ND, Elder DW, La Rossa D, Hamilton R, Bondi E, Tuthill R, Steplewski Z, Koprowski H (1980) Specific immunoreactivity of hybridoma-secreted monoclonal anti-melanoma antibodies to cultured cells and freshly derived human cells. Cancer Res 40:3602-3609

11. Imai K, Ng AK, Ferrone S (1981) Characterization of monoclonal antibodies to human melanoma-associated antigens. J Natl Cancer Inst 66: 489-496

12. Imai K, Natali PG, Kay NE, Wilson BS, Ferrone S (1982a) Tissue distribution and molecular profile of a differentiation antigen detected by a monoclonal antibody (345.134S) produced against human melanoma cells. Cancer Immunol Immunother $12: 159-166$
13. Imai K, Wilson BS, Ruberto G, Nakanishi T, Yachi A, Ferrone $S$ (1982b) Molecular heterogeneity of a high-molecular-weight human melanoma-associated antigen (MAA) detected by monoclonal antibodies. In: Peters $\mathrm{H}$ (ed) Protides of the biological fluids. Pergamon Press, Oxford (Colloquium 29), p 893-897

14. Johnson JP, Demmer-Dieckmann M, Meo T, Haden MR, Reithmuller G (1981) Surface antigens of human melanoma cells defined by monoclonal antibodies. I. Biochemical characterization of two antigens found on cell lines and fresh tumors of diverse tissue origin. Eur J Immunol 11:825-831

15. Kohler G, Milstein C (1975) Continuous cultures of fused cells secreting antibody of predefined specificity. Nature $256: 258-495$

16. Laemmli UK (1970) Cleavage of structural proteins during assembly of the head of bacteriophage T4. Nature 222: 680-685

17. Liao SK, Clarke BJ, Kwong PC, Brickerden A, Gallie B, Dent PB (1981) Common neuroectodermal antigens on human melanoma, neuroblastoma, retinoblastoma, glioblastoma and fetal brain revealed by hybridoma antibodies raised against melanoma cells. Eur J Immunol 11: 450-454

18. Loop SM, Nishiyama K, Hellstrom I, Woodbury RG, Brown JP, Hellstrom KE (1981) Two human tumor-associated antigens $\mathrm{p} 155$ and $\mathrm{p} 210$ detected by monoclonal antibodies. Int $\mathrm{J}$ Cancer 27: 775-781

19. Natali PG, Imai K, Wilson BS, Bigotti A, Cavaliere R, Pellegrino MA, Ferrone S (1981) Structural properties and tissue distribution of the antigen recognized by the monoclonal antibody $653.40 \mathrm{~S}$ to human melanoma cells. J Natl Cancer Inst 67:591-601

20. Reiser J, Wardale J (1981) Immunological detection of specific proteins in total cell extracts by fractionation in gels and transfer to diazophenylthioether paper. Eur J Biochem 114:569-575

21. Salisbury JG, Graham JM (1981) Cell surface radioiodination with the sparingly soluble catalyst Iodogen. Differences between dividing and nondividing thymocytes. Biochem J 194:351-355

22. Segrest JP, Jackson RL, Andrews EP, Marchesi VT (1971) Human erythrocyte membrane glycoproteins: A re-evaluation of the molecular weight as determined by SDS polyacrylamide gel electrophoresis. Biochem Biophys Res Commun 44:390-395

23. Werkmeister J, Edwards A, McCarthy W, Hersey P (1980) Prognostic significance of expression of antigens on melanoma cells. Cancer Immunol Immunother 9: 233-240

24. Wilson BS, Ruberto G, Ferrone S (1981a) Sulfation and molecular weight of fibronectin shed by human melanoma cells. Biochem Biophys Res Commun 101: 1047-1051

25. Wilson BS, Imai K, Natali PG, Bigotti A, Cavaliere R, Pellegrino MA, Ferrone S (1981b) Distribution and molecular characterization of a cell-surface and a cytoplasmic antigen detectable in human melanoma cells with monocional antibodies. Int J Cancer 28: $293-300$

26. Wilson BS, Imai K, Natali PG, Cavaliere R, Pellegrino MA, Ferrone S (1982a) Antigenic profile of human melanoma cells: Analysis with monoclonal antibodies. In: Reisfeld RA, Ferrone S (eds) Melanoma antigens and antibodies. Plenum Press, New York, p 401-433

27. Wilson BS, Giacomini $P$, Imai $K$, Natali PG, Nakanishi $T$, Ruberto G, Ferrone S (1982b) Human melanoma associated antigens identified with monoclonal antibodies: Structural profile and potential usefulness in immunodiagnosis and immunotherapy. Ric Clin Lab (in press)

28. Woodbury RG, Brown JF, Yeh MY, Hellstrom I, Hellstrom KW (1980) Identification of a cell surface protein p97 in human melanoma and certain other neoplasms. Proc Natl Acad Sci USA $77: 2183-2187$

Received August 17, 1982/Accepted November 22, 1982 